\title{
Genome-wide Association Studies and Candidate Gene Identification for Leaf Scald and Net Blotch in Barley (Hordeum vulgare L.)
}

\author{
Sintayehu D. Daba, ${ }^{1}$ Richard Horsley, ${ }^{2}$ Robert Brueggeman, ${ }^{3}$ Shiaoman Chao, ${ }^{4}$ Mohsen Mohammadi ${ }^{1, \dagger}$ \\ ${ }^{1}$ Purdue University, Department of Agronomy, West Lafayette, IN 47907-2053; ${ }^{2}$ North Dakota State University, Department of \\ Plant Sciences, Fargo, ND 58108-6050; ${ }^{3}$ North Dakota State University, Department of Plant Pathology, Fargo, ND 58102-2765; \\ and ${ }^{4}$ USDA-ARS, BRL, Fargo, ND 58102-2765
}

Abstract

\begin{abstract}
We report genomic regions that significantly control resistance to scald, net form (NFNB) and spot form net blotch (SFNB) in barley. Barley genotypes from Ethiopia, ICARDA, and the United States were evaluated in Ethiopia and North Dakota State University (NDSU). Genome-wide association studies (GWAS) were conducted using 23,549 single nucleotide polymorphism (SNP) markers for disease resistance in five environments in Ethiopia. For NFNB and SFNB, we assessed seedling resistance in a glasshouse at NDSU. A large proportion of the Ethiopian landraces and breeding genotypes were resistant to scald and NFNB. Most of genotypes resistant to SFNB were from NDSU. We identified 17, 26, 7, and 1 marker-trait associations (MTAs) for field-scored scald, field-scored net blotch, greenhouse-scored NFNB, and greenhouse-scored SFNB diseases, respectively. Using
\end{abstract}

the genome sequence and the existing literature, we compared the MTAs with previously reported loci and genes for these diseases. For leaf scald, only a few of our MTAs overlap with previous reports. However, the MTAs found for field-scored net blotch as well as NFNB and SFNB mostly overlap with previous reports. We scanned the barley genome for identification of candidate genes within $250 \mathrm{~kb}$ of the MTAs, resulting in the identification of 307 barley genes for the 51 MTAs. Some of these genes are related to plant defense responses such as subtilisin-like protease, chalcone synthase, lipoxygenase, and defensin-like proteins.

Keywords: barley, scald, net blotch, genetics of resistance, GWAS, candidate genes
In barley, scald is a common foliar disease found in most production areas, mainly where cool and moist conditions prevail (Paulitz and Steffenson 2011). Recent studies suggest that barley scald originated independent of barley (Brunner et al. 2007; Linde et al. 2009), probably in northern Europe as a result of a founder effect (Brunner et al. 2007). Net blotch is another barley leaf disease with distribution across most barley producing areas (Ellis and Waller 1973). There are two forms of barley net blotch, namely, net form net blotch (NFNB) caused by Pyrenophora teres f. teres and spot form net blotch (SFNB) caused by Pyrenophora teres f. maculata (Liu et al. 2011). Both leaf scald and net blotch are serious barley diseases worldwide that can cause significant yield losses of up to $50 \%$ and negatively impact grain quality (Adawy et al. 2013).

Scald and net blotch are also among the significant barley diseases in Ethiopia, causing up to 31.5 and $59.0 \%$ of yield loss, respectively (Bekele et al. 2011a, b). In Ethiopia, field research sites such as Bekoji and Koffele are the hot spots for leaf scald and net blotch. These locations usually provide the bulk of disease data for breeding and variety registration. In the United States, scald is considered a minor disease of barley. Therefore, the research for varietal resistance for scald was neglected and undervalued. Net blotch, on the other hand, is an important barley disease in the Upper Midwestern production regions including North Dakota and Montana, which are

${ }^{\dagger}$ Corresponding author: M. Mohammadi; E-mail: Mohamm20@purdue.edu

Funding: This research was supported by the Ethiopian Institute of Agriculture Research (EIAR), International Center for Agricultural Research in Dryland Areas (ICARDA), North Dakota State University, and Purdue College of Agriculture.

*The $\boldsymbol{e}$-Xtra logo stands for "electronic extra" and indicates that four supplementary tables are published online.

Accepted for publication 17 October 2018.

() 2019 The American Phytopathological Society among the three leading barley-production states in the United States (Liu and Friesen 2010).

Breeding for disease resistance is an integral component of crop improvement programs. Thus, breeders are primarily interested in understanding the existing genetic variation in breeding populations, as well as the identification and introduction of new genetic variation. The knowledge of quantitative trait loci (QTLs) is essential for marker-assisted selection, marker-assisted backcrossing, and resistance loci pyramiding. While biparental mapping procedures have been a prime approach to identify QTLs historically, genome-wide association studies (GWAS) are now gaining popularity in crop plants due to improvements in statistical models and genotyping technologies (Zhu et al. 2008). For example, the use of mixed linear models usually reduces excessive false discoveries caused by population structure and familial relatedness.

Marker-trait associations (MTAs) or QTLs conferring resistance to scald were reported in all barley chromosomes except $5 \mathrm{H}$ (Jensen et al. 2002; Hofmann et al. 2013; Li and Zhou 2011; Shtaya et al. 2006; Wang et al. 2014; Williams et al. 2001). Evidence indicates that, to this end, barley has at least 11 genes for leaf scald resistance (Grewal et al. 2008). Most of the QTLs for leaf scald mapped close to the Rrs 1 locus on the long arm of chromosome $3 \mathrm{H}$ and the Rrs 2 locus on the short arm of chromosome $7 \mathrm{H}$. Other leaf scald resistance genes including Rrs1, Rrs3, and Rrs 4 on $3 \mathrm{H}$; Rrs 2 and $R r s 12$ on $7 \mathrm{H} ; \operatorname{Rrs} 6$ and Rrs 9 on $4 \mathrm{H} ; \operatorname{Rrs} 13$ on $6 \mathrm{H}$; and Rrs 14 on $1 \mathrm{H}$ are listed in the GrainGenes database available at https://wheat.pw.usda.gov/ cgi-bin/GG3/browse.cgi?class=gene. The leaf scald resistance genes $\operatorname{Rrs} 12$ on $7 \mathrm{H}$; Rrs 13 on $6 \mathrm{H}$; and $R r s 14$ on $1 \mathrm{H}$ were derived from wild barley (Grewal et al. 2008). Similarly, QTLs were located across all barley chromosomes for NFNB (Grewal et al. 2012; Islamovic et al. 2017; Manninen et al. 2006) and SFNB (Grewal et al. 2012; Manninen et al. 2006; Wang et al. 2015; Williams et al. 1999). For net blotch, a few genes have been indicated in GrainGenes database such as the rpt-k and rpt.r on $6 \mathrm{H} ; R p t 1$ on $3 \mathrm{H} ; R p t 2$ on $1 \mathrm{H} ; R p t 3$ on $2 \mathrm{H}$; and Rpt4 on $7 \mathrm{H}$. Across studies, QTLs were frequently reported on chromosome $3 \mathrm{H}$ for scald and on chromosome $6 \mathrm{H}$ for NFNB. Recently, Wang et al. (2015) used 898 elite genotypes from Australia for SFNB, and they reported 29 QTLs residing in 24 genomic 
regions, implying that SFNB is controlled by a complex genetic system.

The current study was conducted using barley populations sampled from Ethiopian landraces as well as cultivars and breeding genotypes developed in Ethiopia, International Center for Agricultural Research in the Dry Areas (ICARDA), and the North Dakota State University (NDSU) to identify loci that control barley scald and net blotch disease resistance.

\section{Materials and Methods}

Field scored disease severity. Scald and net blotch were scored in field experiments conducted in five environments (year-location combinations) in Ethiopia at Bekoji (2011-2013) and Koffele (2011 and 2012). Bekoji is located at $7.5277^{\circ} \mathrm{N}$ and $39.2531^{\circ} \mathrm{E}$. The site has minimum and maximum temperatures of $7.5^{\circ} \mathrm{C}$ and $15.4^{\circ} \mathrm{C}$, respectively, with average annual rainfall of $1,024 \mathrm{~mm}$. Koffele is located at $7.0764^{\circ} \mathrm{N}$ and $38.7865^{\circ} \mathrm{E}$. The minimum and maximum temperatures for Koffele are $7.1^{\circ} \mathrm{C}$ and $18.0^{\circ} \mathrm{C}$, respectively, with average annual rainfall of $1,211 \mathrm{~mm}$. A total of $184 \mathrm{di}-$ verse barley genotypes were used for field-based screening, which included 29 Ethiopian landraces, 53 Ethiopian breeding genotypes, 81 ICARDA breeding genotypes, and 21 NDSU breeding genotypes. Seventy-six of these genotypes were two-row types, and the remaining 108 genotypes were six-row types. Experiments in 2011 at both locations were laid out in an augmented design with 11 incomplete blocks with four checks repeated in each block. In 2012 and 2013, the entries were planted in a $14 \times 14$ simple lattice design. The plot size was $2.5 \times 1.2 \mathrm{~m}\left(3 \mathrm{~m}^{2}\right)$ in all experiments. Experiments were sown in approximately the second week of June. The scald and net blotch (mixed NFNB and SFNB) disease severity at the adult plant stage were recorded during October-November each year using a $0-9$ scale $(0=$ no infection symptoms and $9=$ highly susceptible $)$ as per Saari and Prescott (1975). Ratings below 2.5 were considered resistant, 2.5-5.0 were considered moderately resistant, and above 5 were considered susceptible.

Seedling disease severity phenotyping. A total of 234 diverse barley genotypes was used for seedling assays, including most of the genotypes tested in the field experiments. The panel was composed of 76 Ethiopian landraces, 40 Ethiopian breeding genotypes, 77 ICARDA breeding genotypes, and 41 NDSU breeding genotypes. In this panel, 104 lines were two-row types and the remaining 130 were six-row types. The genotypes were grown in $3.8 \times 21 \mathrm{~cm}$ Ray Leach 98 cell containers (Stuewe \& Sons, Corvallis, OR) filled with Sunshine mix (3:1 peat moss:perlite) (Sun Gro, Bellevue, WA). Three seeds of each accession were sown in a cone. Each genotype was replicated three times for both NFNB and SFNB. For NFNB, the susceptible check was 'Hector' and the resistant check was 'NDB112'. For SFNB, the susceptible check was 'Pinnacle' and the resistant check was 'CIHO14219'. A total of 15 Ray Leach container racks were used for each disease form, and the checks for both diseases were repeated twice in each rack. The outer cones of each rack were sown with the respective susceptible check to reduce boarder effects. The three replicates for each disease form were planted on three consecutive days.

Suspensions of $P$. teres f. teres isolate ND89-19 and P. teres f. maculata isolate ND111 spores were sprayed on the barley seedlings 12 days after sowing. The spore count was $\sim 5,000$ spores $\mathrm{ml}^{-1}$ for NFNB and $\sim 2,000$ spores $\mathrm{ml}^{-1}$ for SFNB. For each rack, $100 \mathrm{ml}$ of the spore solution was sprayed uniformly. For NFNB, the plants were kept in the dark in a humidity chamber for $20 \mathrm{~h}$. Plants inoculated with SFNB were kept under light and high humidity for $20 \mathrm{~h}$. To maintain $100 \%$ humidity, water was applied as a mist for $30 \mathrm{~s}$ every $4 \mathrm{~min}$ for both diseases.

Following incubation in the humidity chamber, plants were transferred to the greenhouse for disease establishment. Seven days after inoculation, disease severity was recorded from two plants in each
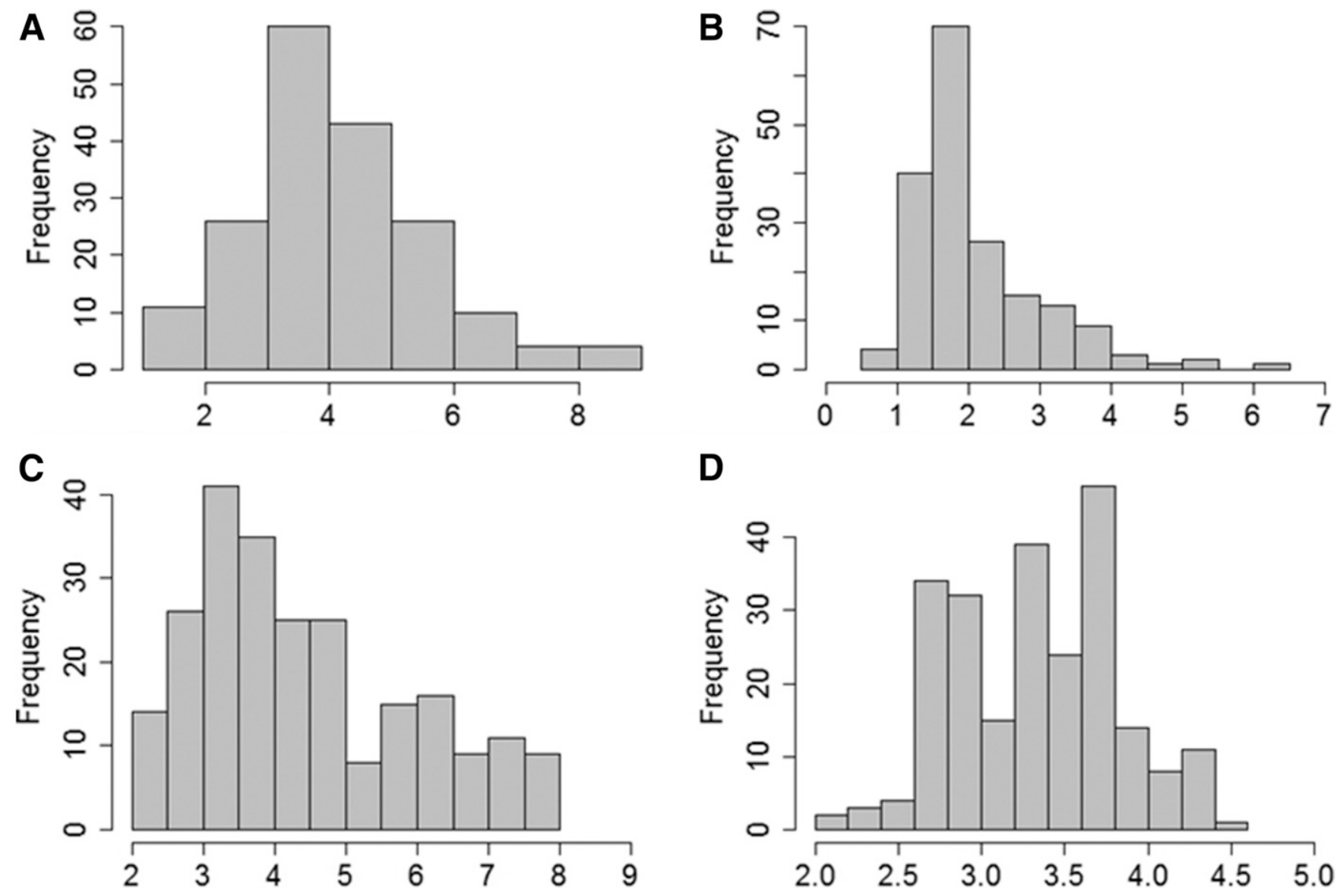

Fig. 1. Phenotypic distributions for: (A) scald (SC) as BLUP estimates of disease susceptibility scores over five environments, (B) net blotch (NB) as BLUP estimates of disease susceptibility scores over five environments for (C) net form net blotch (NFNB) and (D) spot form net blotch (SFNB). 
cone. The NFNB infection rates (IRs) were recorded on the second leaf using a 10-point scale described by Tekauz (1985). Infection rates below five were considered resistant and those five and above were considered susceptible. A five-point scale was used for SFNB, (Neupane et al. 2015), where IRs below 2.5 were considered resistant and IRs 2.5 and above were considered susceptible.

Phenotypic data analysis. Variability in disease severity among genotypes was shown using histograms. The correlation coefficients among the scores for a trait among the five environments (year-location combinations) were used to assess the technical repeatability of the measurements. Boxplots were used to demonstrate the disease response of the four groups of genotypes, i.e., Ethiopian landraces (A), Ethiopian breeding genotypes (B), ICARDA breeding genotypes (C), and NDSU breeding genotypes (D). Broad-sense heritability $\left(\mathrm{H}^{2}\right)$ of the disease responses on entry-mean basis were estimated using the formula from Falconer and Mackay (1996).

$$
H^{2}=\frac{V g}{V g+V e / e}
$$

A

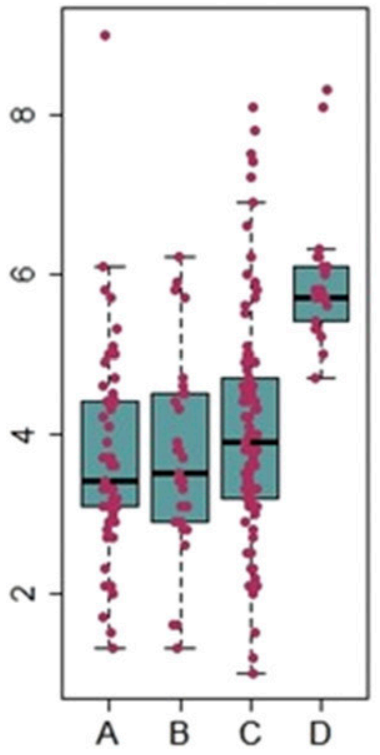

B

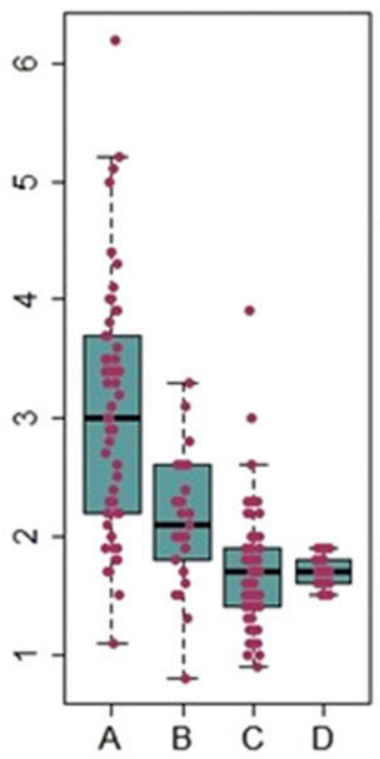

where $V g$ is genotypic variance $V e$ is the residual error.

Generating marker data. Sequencing-based genotyping method (Elshire et al. 2011; Saintenac et al. 2013) was used to produce single nucleotide polymorphisms (SNP) markers. The sequencing was done using the Illumina NextSeq 500 platform. SNP calling was performed using the TASSEL5 GBSv2 pipeline (Glaubitz et al. 2014) using 64-base kmer length and minimum kmer count of 5 by aligning raw reads to the barley reference genome "Hv_IBSC_PGSB_v2" (ftp://ftp.ensemblgenomes.org/pub/plants/release-37/fasta/hordeum_ vulgare/dna/) using the aln method of Burrows-Wheeler aligner (BWA) version 0.7.10 (Li and Durbin 2009). The SNP markers were filtered based on the criteria of minor allele frequency (MAF) $\geq 5 \%$ and missing values $\leq 30 \%$. The missing genotypic data were imputed using the LDKNNi imputation method (Money et al. 2015) available in TASSEL5 (Bradbury et al. 2007).

Linkage disequilibrium (LD) and population structure analysis. Linkage disequilibrium (LD) values were estimated from 23,549 SNP markers for 234 barley genotypes in Tassel5.0 (Bradbury et al. 2007) using a sliding of 50 loci. The LD decay analysis was

Fig. 2. Comparison among four groups of genotypes ( $A=$ Landrace, $B=$ Ethiopian, $C=I C A R D A$, and $D=$ NDSU) for: (A) scald (SC, in scale of 0 to 9$)$ as $B L U P$ estimates over five environments, (B) net blotch (NB, in a scale of 0 to 9 ) as BLUP estimates over five environments, (C) net form net blotch (NFNB, in scale of 0 to 9), and (D) spot form net blotch (SFNB, in a scale of 0 to 5 ).

Table 1. Representative genotypes showing consistent resistant and susceptible field-scored phenotypes for leaf scald across environments. Phenotypes are in a $0-9$ scale $(0=$ no infection symptoms and $9=$ highly susceptible $)$.

\begin{tabular}{|c|c|c|c|c|c|c|c|c|}
\hline \multirow[b]{2}{*}{ Name } & \multirow[b]{2}{*}{ Source } & \multirow[b]{2}{*}{ Row } & \multicolumn{6}{|c|}{ Leaf scald score ${ }^{a}$} \\
\hline & & & BE11 & KO11 & BE12 & KO12 & BE13 & Mean \\
\hline 118105 & LANDRACE & Six-row & 1 & 1 & 2 & 1 & 1 & 1.2 \\
\hline 202572 & LANDRACE & Six-row & 3 & 2 & 2 & 3 & 2 & 2.4 \\
\hline EH1642/F7.3H & ETHIOPIAN & Two-row & 2 & 1 & 1 & 2 & 1 & 1.4 \\
\hline EH1510/F6.48H.2 & ETHIOPIAN & Six-row & 1 & 2 & 2 & 2 & 1 & 1.6 \\
\hline IBOB-MRA 19/05 & ICARDA & Two-row & 0 & 1 & 2 & 2 & 1 & 1.2 \\
\hline IBSP-S 129/06 & ICARDA & Two-row & 1 & 0 & 2 & 1 & 1 & 1.0 \\
\hline BSN 08-TR-1175 & ICARDA & Six-row & 7 & 7 & 9 & 8 & 6 & 7.6 \\
\hline IBON 92-2/99 & ICARDA & Six-row & 8 & 9 & 9 & 6 & 6 & 7.6 \\
\hline Melkasa N. 78/06 & ICARDA & Six-row & 9 & 9 & 9 & 7 & 7 & 8.2 \\
\hline Melkasa N. 81/06 & ICARDA & Six-row & 6 & 9 & 9 & 7 & 7 & 7.4 \\
\hline ND20824/SCARLETT & ICARDA & Two-row & 9 & 7 & 8 & 8 & 5 & 7.4 \\
\hline Pinnacle & NDSU & Two-row & 9 & 9 & 9 & 9 & 7 & 8.6 \\
\hline Stellar-ND & NDSU & Six-row & 8 & 8 & 9 & 9 & 6 & 8.0 \\
\hline
\end{tabular}

a BE11 = Bekoji in 2011, KO11 = Koffele in 2011, BE12 = Bekoji in 2012, KO12 = Koffele in 2012, and BE13 = Bekoji in 2013. 
done using the procedure from Hill and Weir (1988) in R environment ( $\mathrm{R}$ Core Team 2013). The physical distance (Mbp) at the point where LD dropped below half the maximum LD was considered as the LD decay distance. Population structure was assessed using principal component analysis of marker data. The first two principal components were plotted to visualize the population structure.

Genome-wide association study (GWAS). GWAS was completed for scald and net blotch using the 23,549 SNP markers in TASSEL5 (Bradbury et al. 2007), using a mixed linear model (MLM), and only one-time approximation of variance component, described as eXpedited (EMMAX) algorithm (Kang et al. 2010). Our association genetics model included two fixed effects, namely, markers and the first three principal components of the marker data as population structure. Kinship as familial relatedness matrix and residual terms were considered random effects. Manhattan plots were produced using the negative logarithm at base 10 of the $p$-values, shortened as $-\log _{10} P$, using the qqman package of $\mathrm{R}$ (Turner 2014) across the physical map. The SNPs with $-\log _{10} P>4$.0 were identified for further characterization. For field-scored scald and net blotch, the Manhattan plots presented are based on the combined dataset analysis. The GWAS statistics $\left(P\right.$ values, marker effects, and $\left.\mathrm{R}^{2}\right)$ from individual environments were provided as supplemental information. However, the total number of MTAs reported in this study for field-scored scald and net blotch are those that were detected in at least two analyses. Once resistance alleles were identified, we assessed the cumulative effect of the resistance allele combinations in conferring disease resistance.

Linking the MTAs with putative candidate genes. Using a position-dependent strategy, the genomic region upstream and downstream $( \pm 250 \mathrm{~kb})$ of the identified polymorphic sites was scanned to identify genes that are in the physical proximity and in tight LD with the polymorphic site. For this purpose, the annotated barley genome in the Hordeum ensembl (ftp://ftp.ensemblgenomes.org/pub/release-38/plants/gff3/hordeum_vulgare) was used. For each barley gene retrieved, the coding sequence was blasted against the NCBI nr database for further functional annotation. For a select number of MTAs, a list of genomic sequences harboring the polymorphic sites to allow follow-up marker development studies was generated.

\section{Results}

Field-based scald disease response. The tested genotypes showed a wide range of variation in their responses to scald disease in the field environments, with a minimum disease score of 1.0 to a maximum of 9.0 (Fig. 1A). Genotypes from Ethiopia appeared to be more resistant to scald disease compared with other genotypes, particularly from NDSU (Fig. 2A). About $85 \%$ of the landraces, $86 \%$ of Ethiopian breeding genotypes, and $79 \%$ of ICARDA genotypes showed resistance $($ score $<5.0$ ) to scald disease; whereas $95 \%$ of NDSU genotypes showed susceptible phenotypes (scores $\geq 5.0$ ), indicating that NDSU genotypes are generally susceptible to leaf scald. The Ethiopian breeding line EH1642/F7.3H and landrace accession 118105 were among the genotypes with consistently low scald scores, while the NDSU cultivars Pinnacle and Stellar-ND were among the genotypes highly susceptible to scald (Table 1).

Field-based net blotch disease response. Across the five field environments, we observed a narrow range of variation for net blotch resistance (Fig. 1B). A relatively low (2.2) mean disease severity (based on LSMEANS) across the five field environments was observed, with a range from 0.8 to 6.2. Genotypes from Ethiopia, NDSU, and ICARDA exhibited some degrees of resistance for net blotch (Fig. 2B); whereas Ethiopian landraces showed large variability in resistance to the naturally occurring net blotch in Ethiopia. Genotypes that consistently demonstrated resistant phenotypes across environments include EH1847/F4.2P.5.2 and EMBSN 9306/05 (Table 2). In contrast, the landrace accessions 117992 and 118078 were consistently susceptible across all environments.

Seedling responses to NFNB and SFNB. The average phenotypic response for NFNB was 4.5 , with a wide range of variability from 2.0 to 7.9 (Fig. 1C). Most of the landraces (92\%) and Ethiopian breeding genotypes $(90 \%)$ showed seedling resistance (score $<5.0)$ to the North Dakota NFNB isolate ND89-19 (Fig. 2C). Only 57\% of the ICARDA and $39 \%$ of the NDSU genotypes showed resistant phenotypes (scores $<5.0$ ) to the same isolate.

The mean SFNB phenotypic response was 3.4, ranging from 2.0 to 4.5 (Fig. 1D). There were very few genotypes in the panel with a mean SFNB severity score $<2.5$, which could be classified as resistant (Fig. 2D). The NDSU breeding genotypes possessed the highest frequency $(7.3 \%)$ of resistance phenotypic response. The frequency of resistant genotypes to SFNB in landraces and ICARDA genotypes were 2.6 and $3.9 \%$, respectively. The mean SFNB scores of the susceptible and resistance checks used in this experiment were 3.2 and 1.3 , respectively.

The disease scores for representative resistant and susceptible genotypes are given in Table 3. Particularly, the six-rowed NDSU genotypes were susceptible to both NFNB and SFNB. An Ethiopian

Table 3. Representative genotypes showing consistent resistant and susceptible greenhouse-scored phenotypes for net form net blotch (NFNB) and spot form net blotch (SFNB). Phenotypes for NFNB are in a $0-9$ scale $(0=$ no infection symptoms and $9=$ highly susceptible), while phenotypes for SFNB are in a $1-5$ scale $(1=$ no infection symptoms and $5=$ highly susceptible $)$.

\begin{tabular}{lllcc}
\hline Name & Source & Row & NFNB & SFNB \\
\hline 37529 & LANDRACE & Six-row & 3 & 2 \\
2ND27705 & NDSU & Two-row & 2 & 2 \\
2ND30681 & NDSU & Two-row & 2 & 2 \\
IBON 114/99 & ICARDA & Six-row & 8 & 3 \\
ND27245 & NDSU & Six-row & 8 & 3 \\
ND29144 & NDSU & Six-row & 8 & 4 \\
ND29151 & NDSU & Six-row & 8 & 3 \\
ND30057 & NDSU & Six-row & 7 & 3 \\
ND28555 & NDSU & Six-row & 8 & 3 \\
ND28993 & NDSU & Six-row & 8 & 3 \\
\hline
\end{tabular}

Table 2. Representative genotypes showing consistent resistant and susceptible field-scored phenotypes for net blotch across environments. Phenotypes are in a $0-9$ scale $(0=$ no infection symptoms and $9=$ highly susceptible $)$.

\begin{tabular}{|c|c|c|c|c|c|c|c|c|}
\hline \multirow[b]{2}{*}{ Name } & \multirow[b]{2}{*}{ Source } & \multirow[b]{2}{*}{ Row } & \multicolumn{6}{|c|}{ Net blotch score } \\
\hline & & & BE11 & KO11 & BE12 & KO12 & BE13 & Mean \\
\hline EH1847/F4.2P.5.2 & ETHIOPIAN & Two-row & 1 & 0 & 1 & 2 & 1 & 1.0 \\
\hline EMBSN 9306/05 & ICARDA & Two-row & 1 & 1 & 1 & 1 & 1 & 1.0 \\
\hline Estayish (218963-4) & LANDRACE & Six-row & 1 & 2 & 1 & 1 & 1 & 1.2 \\
\hline IBON 74/03 & ICARDA & Two-row & 2 & 0 & 1 & 1 & 3 & 1.4 \\
\hline IBON 9063/05 & ICARDA & Two-row & 1 & 2 & 1 & 2 & 1 & 1.4 \\
\hline IBON 9104/06 & ICARDA & Two-row & 1 & 2 & 1 & 1 & 1 & 1.2 \\
\hline 117992 & LANDRACE & Six-row & 6 & 5 & 4 & 6 & 5 & 5.2 \\
\hline 118078 & LANDRACE & Six-row & 6 & 7 & 7 & 7 & 4 & 6.2 \\
\hline 118105 & LANDRACE & Six-row & 6 & 3 & 6 & 7 & 4 & 5.2 \\
\hline
\end{tabular}

a BE11 = Bekoji in 2011, KO11 = Koffele in 2011, BE12 = Bekoji in 2012, KO12 = Koffele in 2012, and BE13 = Bekoji in 2013. 
landrace (37529) and two NDSU two-row genotypes (2ND27705 and 2ND30681) were resistant for both NFNB and SFNB.

Heritability estimates. The broad-sense heritability estimates were relatively high for the four disease responses in this study (Table 4). The estimates range from a low of $38.2 \%$ for NFNB to a high of $78.0 \%$ for net blotch scored in the field under natural infection.

Linkage disequilibrium (LD) decay and population structure. The LD decay dropped below half the maximum at $457 \mathrm{~kb}$ (Fig. 3). The population structure showed stratification based on the origin of the materials (Fig. 4). For instance, the Ethiopian landraces were completely separated from the NDSU breeding materials. In addition to the geographic origin, the inflorescence type (two-row versus sixrow) was another source of population stratification. This could be exemplified with the two distinct groups of breeding lines from the NDSU breeding program.

GWAS for leaf scald in field condition. The GWAS for leaf scald over all the analyses resulted in 17 MTAs based on the criteria of $-\log _{10} P \geq 4.0$ (Fig. 5A). These MTAs were located in 16 genomic regions on all chromosomes except $4 \mathrm{H}$. Some of these MTAs were unique to a single environment and some were identified in multiple environments. Three of the MTAs ( $Q s c-1 H$, Qsc-5H.3, and $Q s c-$ $7 H .3)$ were detected in the combined analysis and in one individual environmental analysis (Fig. 5A and Table 5). Qsc-7H.1 was also detected in two individual environmental analyses.

The highest association signal for scald was detected for Qsc-7H.1 at Koffele in 2012 with $-\log _{10} P$ of 6.7 , which was also identified at Bekoji in 2012. This MTA explained $16 \%$ of the variations in leaf scald resistance at Koffele in 2012, with the resistant allele associated with a reduction in disease susceptibility by 2.5 units. The second strongest association signal for leaf scald was observed at Bekoji in 2012 with $-\log _{10} P$ of 5.6 for $Q s c-7 H .3$. This MTA was also detected in combined analysis. Qsc-7H.3 explained $15 \%$ of the variation in phenotypic data at Bekoji in 2012. The resistant allele at this locus reduced the susceptibility score by 1.2 units, in a scale of 0 to 9 . The third highest signal was for $Q s c-5 H .3$ with $-\log _{10} P$

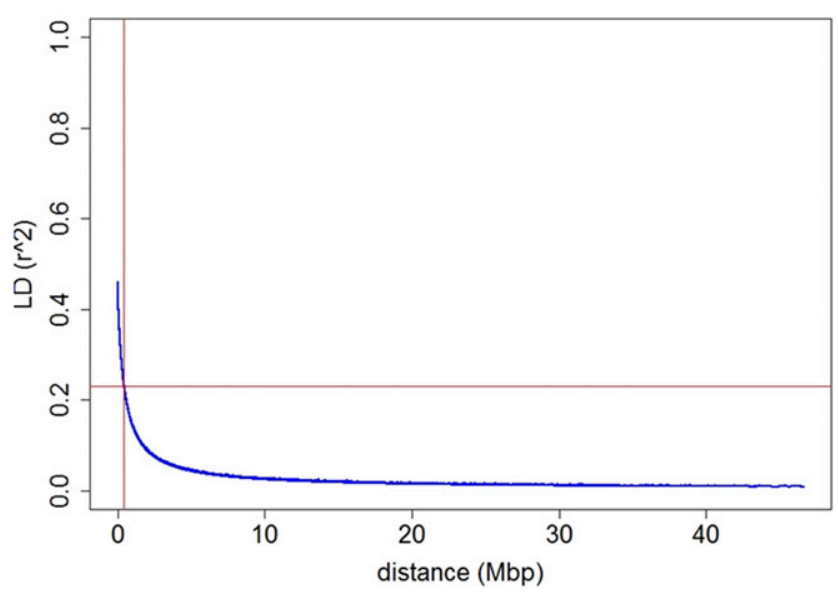

Fig. 3. Linkage disequilibrium (LD) decay, where the $L D$, in terms of $r^{2}$, plotted against physical distance (Mbp). Pairwise $r^{2}$ values are calculated in sliding windows of 50 loci. The horizontal line indicates half the maximum LD, while the vertical line indicates the distance $(457 \mathrm{~kb})$ at which the LD dropped to half of the initial maximum LD.

Table 4. Estimates of the genotypic (g), environmental (e), and phenotypic (p) variances and broad-sense heritability for leaf scald, net blotch scored in the field, net form net blotch (NFNB), and spot form net blotch (SFNB)

\begin{tabular}{lccccc}
\hline Disease & $\boldsymbol{\sigma}^{\mathbf{2}} \mathbf{g}$ & $\boldsymbol{\sigma}^{\mathbf{2}} \mathbf{c}$ & $\boldsymbol{\sigma}^{\mathbf{2}} \mathbf{p}$ & $\mathbf{h}^{\mathbf{2}}(\boldsymbol{\%})$ & $\mathbf{n}$ \\
\hline Leaf scald & 0.601 & 0.960 & 0.793 & 75.8 & 5 \\
Net blotch & 1.613 & 2.274 & 2.068 & 78.0 & 5 \\
NFNB & 0.370 & 1.793 & 0.968 & 38.2 & 3 \\
SFNB & 0.168 & 0.196 & 0.233 & 72.0 & 3 \\
\hline
\end{tabular}

of 4.9, which explained $10 \%$ of variation at Koffele in 2011 with an allele effect size of 1.6 unit in a scale of 0 to 9 . The locus $Q s c$ $1 H$ was detected in two analyses, Bekoji in 2013 and combined data. In the combined analysis, $Q s c-1 H$ explained $12 \%$ of variation with the allele effect size of 0.8 units in a 0 to 9 scale.

Most of the entries (86\%) contained 5 to 12 resistant alleles in their genetic background (Fig. 6A). As expected, the leaf scald disease susceptibility score decreased as the resistant alleles accumulated. For example, the mean disease susceptibility of entries with five resistant alleles $(n=8)$ was 5.0 units, while the mean disease susceptibility of the entries with 12 resistant alleles $(n=11)$ was 3.7 units, a difference of 2.3 units.

GWAS for net blotch in field condition. Over the six analyses, the GWAS for net blotch identified 26 MTAs, with $-\log _{10} P \geq 4.0$ (Fig. 5B and Supplementary Table S1). Twenty-two were detected in two or more environments. Chromosome $5 \mathrm{H}$ contained five of these MTAs. The three MTAs with the greatest significance levels were on chromosomes $1 \mathrm{H}, 3 \mathrm{H}$, and $5 \mathrm{H}$ (Table 5). The first one was $Q n b-1 H$, with $-\log _{10} P$ of 11.7 at Bekoji 2012. This MTA explained $27 \%$ of the variation in resistance to net blotch and had an allele effect size of 0.19. It was also detected at Bekoji in 2011 and in the combined analysis. The second MTA was Qns-3H.5, with the strongest signal identified at Bekoji in $2012\left(-\log _{10} P=10\right)$. This MTA explained $24 \%$ of the resistance to net blotch with an allele effect size of 5.7. The same MTA was also identified at Bekoji in 2011 and in the combined analysis. The third largest signal was detected for Qns-5H.1 in Bekoji in $2012\left(-\log _{10} P=9.9\right)$, which explained $23 \%$ of the resistance with an allele effect size of 0.2 . In addition, this MTA was also detected at Bekoji in 2011 and in the combined analysis. Four MTAs, namely, Qns-4H.2, Qns-5H.3, Qns-6H.2, and Qns$6 H .5$, were detected in four or more analyses. One of the MTA on $6 \mathrm{H}$ $(Q n s-6 H .2)$ was detected in five of the six analyses with $-\log _{10} P$ values as high as 8.9. The MTA Qns-6H.5 was detected in four analyses and explained up to $15 \%$ of phenotypic variation.

About $79 \%$ of the entries contained 11 to 18 resistant alleles at the MTA loci in their genetic background (Fig. 6B). As expected, the disease susceptibility score decreased as the number of resistant alleles increased. For example, genotypes having 11 resistant alleles $(n=10)$ showed a mean disease score of 3.0, while genotypes having 18 resistant alleles $(n=18)$ demonstrated a mean disease score of 1.7 , a difference of 1.3

GWAS for NFNB and SFNB measured in the greenhouse. The association mapping of resistance to the single isolates of both NFNB and SFNB were assessed at the seedling stage in the greenhouse. Seven MTAs were identified for NFNB at $-\log _{10} P \geq 4.0$ (Fig. 5C) on chromosomes $2 \mathrm{H}, 4 \mathrm{H}$, and $6 \mathrm{H}$ (Table 5). The highest association signal for NFNB was for $Q n f n b-6 H .4$, with $-\log _{10} P$ of 5.5. This MTA explained $9 \%$ of resistance to NFNB with an allele effect of 2.3 units. Two MTAs on chromosome 6H (Qnfnb-6H.2 and Qnfnb-6H.3)

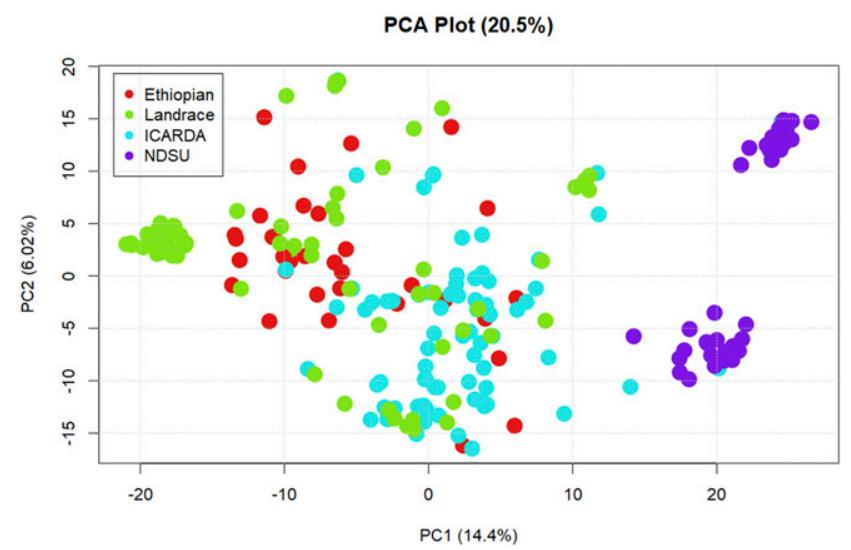

Fig. 4. Scatter plot of the first two principal components estimated from 23,549 SNP markers. 
showed $-\log _{10} P$ of 4.7 and 4.9 , and they explained 7.5 and $7.8 \%$ of the resistance, respectively. Qnfnb-4H.2 was the fourth highest signal for NFNB and was detected on chromosome $4 \mathrm{H}$. This locus explained $8.4 \%$ of the resistance to NFNB with the allele effect of 1.5 units.
The barley entries in this panel contained 0-7resistant alleles in their genetic background (Fig. 6C). Those having zero resistant alleles ( $n=$ 20) showed a disease response score of 7.3; however, those with seven resistant alleles $(n=3)$ showed a disease response score of 2.3.
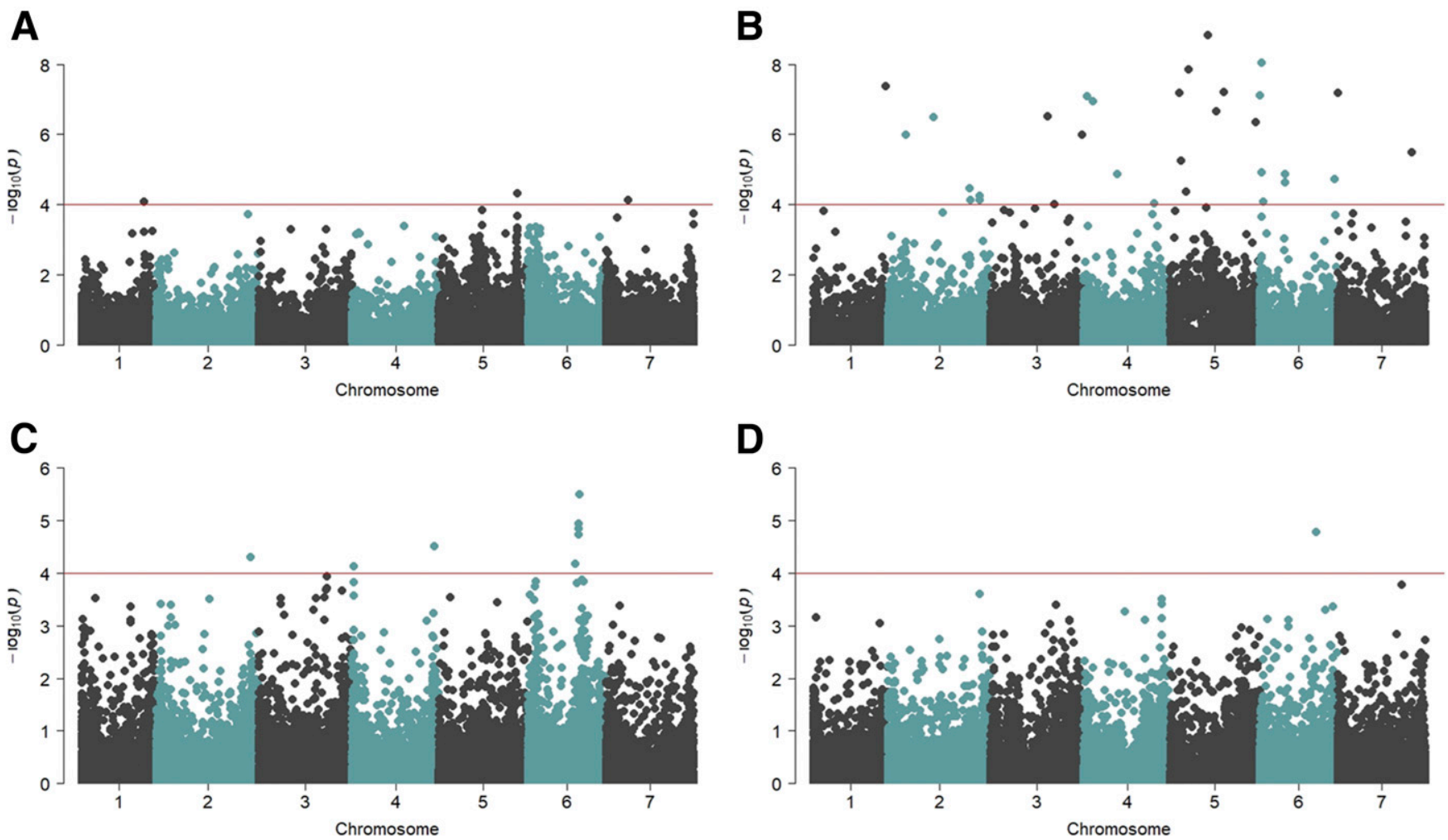

Fig. 5. Manhattan plots demonstrating $-\log _{10}(\mathrm{p})$ values of GWAS procedures for barley diseases across the seven barley chromosomes $(1=1 \mathrm{H}, 2=1 \mathrm{H}, 3=1 \mathrm{H}, 4=4 \mathrm{H}, 5=5 \mathrm{H}$, $6=6 \mathrm{H}$, and $7=7 \mathrm{H})$ : $(\mathbf{A})$ field scored scald in Ethiopia $(\mathbf{B})$ for net form net blotch, $(\mathbf{C})$ for spot form net blotch, and (D) for field-scored net blotch Ethiopia.

Table 5. Marker-trait associations (MTAs), significance level $\left(-\log _{10} P\right)$, percent variation of trait explained $\left(R^{2}\right)$, and allelic effect sizes, and the analysis in which the signal was detected

\begin{tabular}{|c|c|c|c|c|c|c|c|c|}
\hline MTA loci & SNP & Chromosome & Position & Variants & Max $-\log 10(P)$ & $\operatorname{Max} \mathbf{R}^{2}$ & Effect & Detected in ${ }^{a}$ \\
\hline \multicolumn{9}{|c|}{ Field-scored leaf scald } \\
\hline Qsc-1H & S1H_463825184 & $1 \mathrm{H}$ & 463825184 & $\underline{\mathrm{A} / \mathrm{G}}$ & 4.4 & 12.3 & -0.8 & BE13, combined \\
\hline Qsc-5H.3 & S5H_587435242 & $5 \mathrm{H}$ & 587435242 & $\overline{\mathrm{G}} / \mathrm{T}$ & 4.9 & 9.5 & -1.6 & KO11, combined \\
\hline Qsc-7H.1 & S7H_84013770 & $7 \mathrm{H}$ & 84013770 & $\overline{\mathrm{C}} / \mathrm{T}$ & 6.7 & 15.6 & -2.5 & $\mathrm{BE} 12, \mathrm{KO} 12$ \\
\hline Qsc-7H.3 & S7H_165483578 & $7 \mathrm{H}$ & 165483578 & $\overline{\mathrm{A}} / \mathrm{G}$ & 5.6 & 14.9 & -1.2 & BE12, combined \\
\hline \multicolumn{9}{|c|}{ Field-scored net blotch } \\
\hline Qns-1H & S1H_544039452 & $1 \mathrm{H}$ & 544039452 & $\mathrm{~A} / \mathrm{G}$ & 11.7 & 26.0 & -0.07 & BE11, BE12, combined \\
\hline Qns-3H.5 & S3H_685962845 & $3 \mathrm{H}$ & 685962845 & $\overline{\mathrm{C}} / \mathrm{T}$ & 10.0 & 24.1 & 5.67 & BE11, BE12, combined \\
\hline Qns-4H.2 & S4H_66009278 & $4 \mathrm{H}$ & 66009278 & $\mathrm{C} / \overline{\mathrm{T}}$ & 9.3 & 22.8 & -0.12 & BE11, BE12, BE13, combined \\
\hline Qns-5H.1 & S5H_69840012 & $5 \mathrm{H}$ & 69840012 & $\overline{\mathrm{A}} / \mathrm{G}$ & 9.9 & 22.6 & -0.20 & BE11, BE12, combined \\
\hline Qns-5H.3 & S5H_139242182 & $5 \mathrm{H}$ & 139242182 & $\overline{\mathrm{C}} / \underline{\mathrm{T}}$ & 9.1 & 18.5 & 0.62 & BE11, BE12, KO12, combined \\
\hline Qns-5H.4 & S5H_282172561 & $5 \mathrm{H}$ & 282172561 & $\mathrm{~A} / \overline{\mathrm{G}}$ & 9.3 & 22.7 & -0.27 & BE11, BE12, combined \\
\hline Qns-5H.6 & S5H_402794868 & $5 \mathrm{H}$ & 402794868 & $\overline{\mathrm{A}} / \mathrm{G}$ & 9.7 & 22.2 & 0.20 & BE11, BE12, combined \\
\hline Qns-6H.2 & S6H_11444194 & $6 \mathrm{H}$ & 11444194 & $\mathrm{~A} / \overline{\mathrm{G}}$ & 8.9 & 17.0 & -0.05 & BE11, BE12, KO11, KO12, combined \\
\hline Qns-6H.5 & S6H_192295204 & $6 \mathrm{H}$ & 192295204 & $\overline{\mathrm{G}} / \mathrm{T}$ & 5.2 & 14.1 & 4.53 & BE11, BE12, BE13, combined \\
\hline Qns-7H.1 & S7H_2213657 & $7 \mathrm{H}$ & 2213657 & $\mathrm{G} / \overline{\mathrm{T}}$ & 9.6 & 21.8 & -0.06 & BE11, BE12, combined \\
\hline \multicolumn{9}{|c|}{ Net form net blotch (NFNB) } \\
\hline Qnfnb-2H.1 & S2H_708489860 & $2 \mathrm{H}$ & 708489860 & $\underline{\mathrm{G}} / \mathrm{A}$ & 4.3 & 6.8 & 1.55 & Greenhouse study \\
\hline Qnfnb-4H.1 & S4H_10160421 & $4 \mathrm{H}$ & 10160421 & $\overline{\mathrm{C}} / \mathrm{T}$ & 4.1 & 6.5 & 0.88 & Greenhouse study \\
\hline Qnfnb-4H.2 & S4H_613393206 & $4 \mathrm{H}$ & 613393206 & $\overline{\mathrm{A}} / \mathrm{G}$ & 4.5 & 8.4 & 1.48 & Greenhouse study \\
\hline Qnfnb-6H.1 & S6H_353473922 & $6 \mathrm{H}$ & 353473922 & $\underline{\overline{\mathrm{T}}} / \mathrm{C}$ & 4.2 & 6.6 & 1.23 & Greenhouse study \\
\hline Qnfnb-6H.2 & S6H_377801225 & $6 \mathrm{H}$ & 377801225 & $\overline{\mathrm{C}} / \mathrm{T}$ & 4.7 & 7.5 & 1.23 & Greenhouse study \\
\hline Qnfnb-6H.3 & S6H_380651459 & $6 \mathrm{H}$ & 380651459 & $\overline{\mathrm{G}} / \mathrm{A}$ & 4.9 & 7.8 & 1.14 & Greenhouse study \\
\hline Qnfnb-6H.4 & S6H_384875308 & $6 \mathrm{H}$ & 384875308 & $\overline{\mathrm{G}} / \mathrm{T}$ & 5.5 & 8.8 & 2.29 & Greenhouse study \\
\hline \multicolumn{9}{|c|}{ Soft form net blotch (SFNB) } \\
\hline Qsfnb-6H & S6H_422811909 & $6 \mathrm{H}$ & 422811909 & $\mathrm{~A} / \mathrm{G}$ & 4.8 & 10.2 & 0.29 & Greenhouse study \\
\hline
\end{tabular}

a BE11 = Bekoji in 2011, BE12 = Bekoji in 2012, BE13 = Bekoji in 2013, KO12 = Koffele in 2012, KO13 = Koffele in 2013, and combined = combined analysis across the five environments. 
For resistance to SFNB, we detected only one MTA at $-\log _{10} P \geq 4.0$, $Q s f n b-6 H$ on chromosome 6H (Fig. 5C). $Q s f n b-6 H$ was identified with a $-\log _{10} P$ of 4.8 , with allele effect size of 0.3 that explained $10 \%$ of resistance to SFNB. We also searched to find regions, which confer multiple resistance. The closest MTA for NFNB (Qnfnb-6H.4) identified on $6 \mathrm{H}$ was located $37.9 \mathrm{Mbp}$ from $Q s f n b-6 H$.

Barley genes near to the MTAs. The genomic regions around the identified MTAs were examined to comprise a list of putative
A

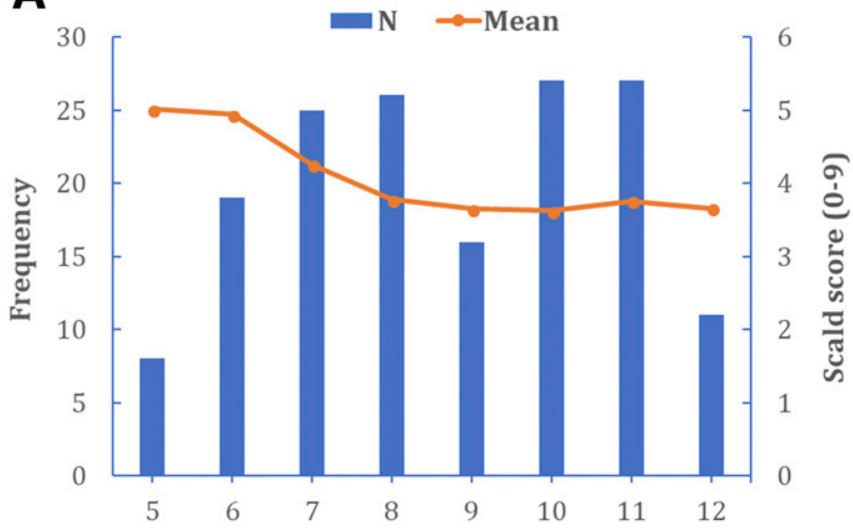

Favorable allele combinations
B

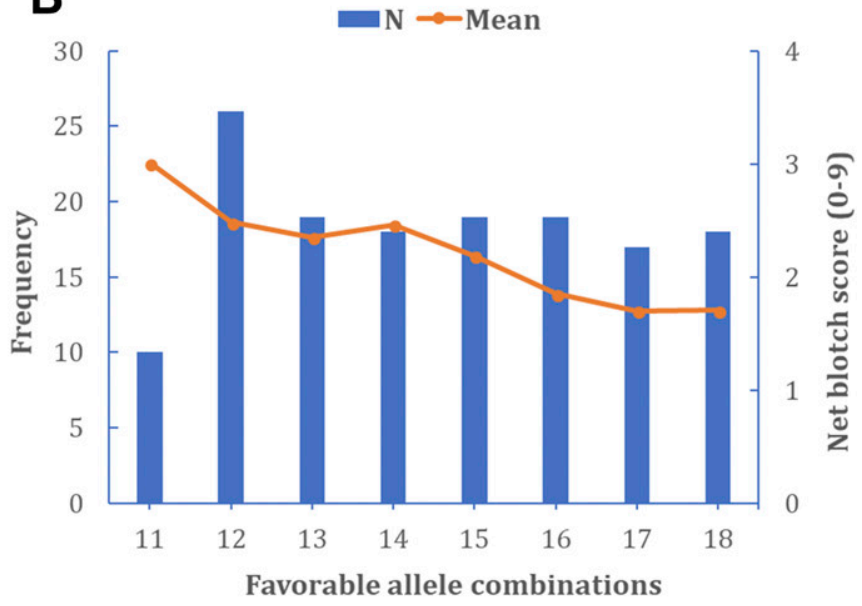

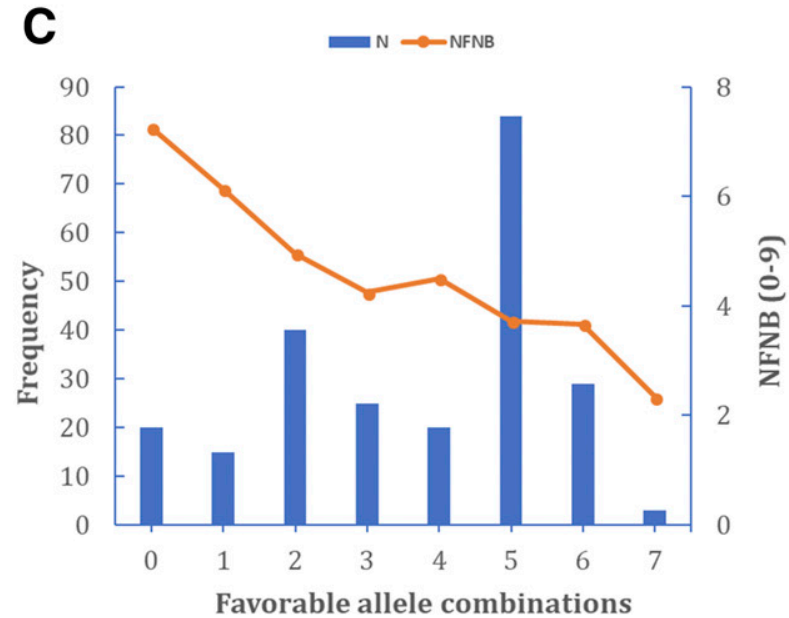

Fig. 6. Cumulative effects of resistant alleles, which results in a clear decrease of disease susceptibility scores for (A) leaf scald, (B) net blotch, and (C) NFNB.

Table 6. The barley genes found nearby the polymorphic sites for the two forms of net blotch

\begin{tabular}{|c|c|c|c|c|}
\hline MTA loci & Gene ID & Description & Functions & Reference \\
\hline \multirow[t]{3}{*}{ Qnb-1H } & HORVU1Hr1G089380 & Subtilisin-like protease & Plant-pathogen interaction & Figueiredo et al. (2014) \\
\hline & HORVU1Hr1G089530 & Sugar transporter & Target for pathogen & Chen and Hou (2010) \\
\hline & HORVU1Hr1G089540 & Calcone syntase & Phytoalexin production & Dao et al. (2011) \\
\hline Qnfnb-2H.1 & HORVU2Hr1G105980 & E3 ubiquitin-protein ligase & Regulating RLK & Goff and Ramonell (2007) \\
\hline \multirow[t]{2}{*}{ Qnb-3H.5 } & HORVU3Hr1G112190 & F-box/LRR-repeat protein & Response to pathogens & Goff and Ramonell (2007) \\
\hline & HORVU3Hr1G112250 & F-box/LRR-repeat protein & Response to pathogens & Goff and Ramonell (2007) \\
\hline Qnb-5H.1 & HORVU5Hr1G017800 & Universal stress protein family protein & Defense to stresses & Tkaczuk et al. (2013) \\
\hline Qnb-5H.3 & HORVU5Hr1G025430 & $\begin{array}{l}\text { Acyl-CoA-binding domain-containing } \\
\text { protein }\end{array}$ & Defense to stresses & Xiao and Chye (2011) \\
\hline \multirow[t]{3}{*}{ Qnb-5H.7 } & HORVU5Hr1G114030 & $\begin{array}{l}\text { L-type lectin-domain containing receptor } \\
\text { kinase }\end{array}$ & Stimuli reception & (Wang and Bouwmeester 2017) \\
\hline & HORVU5Hr1G114100 & $\begin{array}{l}\text { L-type lectin-domain containing receptor } \\
\text { kinase }\end{array}$ & Stimuli reception & (Wang and Bouwmeester 2017) \\
\hline & HORVU5Hr1G114220 & NDR1/IN1-like protein & Defense signaling & Knepper et al. (2011) \\
\hline \multirow[t]{2}{*}{ Qnb-6H.1 } & HORVU6Hr1G000480 & Wall-associated receptor kinase & Stimuli reception & Yang et al. (2014) \\
\hline & HORVU6Hr1G000510 & Lipoxygenase & Defense mechanism & Noordermeer et al. (2001) \\
\hline \multirow[t]{3}{*}{ Qnb-6H.2 } & HORVU6Hr1G005140 & Defensin-like protein & Antimicrobial & Zhang et al. (2013) \\
\hline & HORVU6Hr1G005150 & Defensin-like protein & Antimicrobial & Zhang et al. (2013) \\
\hline & HORVU6Hr1G005250 & Fatty acid hydroperoxide lyase & Defense mechanism & Noordermeer et al. (2001) \\
\hline Qnfnb-6H.4 & HORVU6Hr1G058730 & Pentatricopeptide repeat-containing protein & Mediate gene expression & Manna (2015) \\
\hline Qnb-7H.1 & HORVU7Hr1G000950 & Disease resistance protein RGA3 & & \\
\hline
\end{tabular}


candidate genes. We restricted the gene search only within $250 \mathrm{~kb}$ of the SNPs representing the MTAs. This distance is below the LD decay of $457 \mathrm{~kb}$ in the current mapping panel (Fig. 3). We retrieved 307 barley genes for 51 MTAs and presented them in Supplementary Table $\mathrm{S} 2$. The genes involved in a plant defense system response to biotic and abiotic stresses are listed in Tables 6 and 7. Examples include subtilisin-like protease, chalcone synthase, E3 ubiquitinprotein ligase, lipoxygenase, defensin-like protein, receptor-like kinases, and pentatricopeptide repeat-containing protein.

\section{Discussions}

Leaf scald and net blotch are damaging leaf diseases of barley that cause yield and quality loss. The current study leveraged disease phenotyping work conducted on two continents, Ethiopia in Africa and the United States (North Dakota) in North America. We identified marker-trait associations for the loci that are responsible for resistance to leaf scald and net blotch diseases.

The quest for novel sources of disease resistance via genotype exchange or introductions from gene banks is a common practice in cereal breeding programs. Our study characterized genotypes from Ethiopia (landraces and breeding materials), ICARDA, and NDSU for resistance to leaf scald and net blotch (NFNB and SFNB). Most of the genotypes from Ethiopia exhibited some level of resistance to leaf scald, which may indicate the contribution of breeding and coevolution of the host alongside the pathogen over adaptation history of barley in Ethiopia. The NDSU breeding genotypes were susceptible to scald. This general susceptibility is not surprising because the disease has been minor in the region; hence the NDSU barley breeding program never bred for leaf scald resistance. Most of NDSU breeding genotypes were resistant to net blotch in the field under natural infections in Ethiopia. Several Ethiopian genotypes exhibited seedling resistance to the NFNB pathotype from North Dakota under glasshouse screening. The low frequency of breeding genotypes that were resistant to SFNB indicates a need for lines bred for resistance against this disease. Generally, this study provides an opportunity to find resistant genotypes for breeding purposes. To facilitate the use of the resistant genotype in breeding and research, we reported the most resistant genotypes for the four diseases in Supplementary Table S3.

We identified 17 MTAs for leaf scald on all chromosomes, except $4 \mathrm{H}$, based on five field measurements in Ethiopia and combined data analysis. Multiple MTAs for leaf scald suggested that resistance to leaf scald is multigenic and inherited quantitatively. Analysis of cumulative effects of the resistant alleles also supported this conclusion (Fig. 6A). Previously, QTLs conferring resistance to leaf scald were reported in all barley chromosomes except 5H (Hofmann et al. 2013; Jensen et al. 2002; Li and Zhou 2011; Shtaya et al. 2006; Wang et al. 2014; Williams et al. 2001). Therefore, the three MTAs identified on chromosome $5 \mathrm{H}$ could be novel QTLs.

The availability of the genome sequence (Mascher et al. 2017) and the sequencing-based genotypic data used in this study allows us to approximate the physical positions of previously reported QTLs. Such approximation provides an understanding of physical distance between the loci identified in this study and those identified in earlier studies using microsatellite or SNP array markers. For example, the leaf scald gene Rrs 14 on chromosome $1 \mathrm{H}$ was marked by Hor 2 (Garvin et al. 2000) and MWG835A (Wang et al. 2014) markers and was located 461.2 Mbp apart from the only MTA we identified on $1 \mathrm{H}(Q s c-1 H)$. This sizeable physical distance indicates that $Q s c-1 H$, the MTA we identified on $1 \mathrm{H}$, is different from the previously reported Rrs14. A BOPA SNP marker, 12_31497, was linked to the genomic region conferring resistance to leaf scald (T3/barley database). Using blast alignment, we positioned the BOPA SNP 12_31497 at $\sim 13 \mathrm{Mbp}$ of chromosome 2H. Qsc-2H.2 is $4.2 \mathrm{Mbp}$ away from 12_31497. Therefore, it is possible that $12 \_31497$ marked the same region as $Q s c-2 H .2$. Evidence indicated that chromosome $3 \mathrm{H}$ was implicated for at least one QTL for resistance to leaf scald in past studies (Hofmann et al. 2013; Jensen et al. 2002; Li and Zhou 2011; Wang et al. 2014; Williams et al. 2001). We also identified one region on chromosome $3 \mathrm{H} \sim 77.6 \mathrm{Mbp}$ away from the Rrs1, which was previously marked by $1 \_0452$ (Wang et al. 2014), implying that these two regions are different.

Using data from five field experiments in Ethiopia and combined data, our GWAS identified 26 MTAs for field-scored net blotch on all chromosomes with $-\log _{10} P$ reaching 11.7. Similar to leaf scald disease, the large number of MTAs for net blotch indicated that resistance to net blotch is inherited quantitatively. We also studied the genetics of the two forms (i.e., NFNB and SFNB) of net blotch in the greenhouse condition. Our GWAS resulted in the identification of seven MTAs for NFNB on chromosomes $2 \mathrm{H}, 4 \mathrm{H}$, and $6 \mathrm{H}$. In addition, our GWAS resulted in one MTA for SFNB on chromosome $6 \mathrm{H}$. The identification of just one MTA for SFNB could be related to the fact that most of the genotypes in the current panel were susceptible to this disease.

Previous studies have identified quantitative trait loci conferring resistance to NFNB on all chromosomes (Abu Qamar et al. 2008; Adawy et al. 2013; Amezrou et al. 2018; Grewal et al. 2008, 2012; Gupta et al. 2010, 2011; Manninen et al. 2006; Richards et al. 2016). The consensus is that $6 \mathrm{H}$ consisted of a common yet complex resistance locus. Similarly, we observed that chromosome $6 \mathrm{H}$ had the most MTAs for NFNB. For SFNB, QTLs were reported previously across all barley chromosomes (Grewal et al. 2012; Manninen et al. 2006; Wang et al. 2015; Williams et al. 1999). Using 898 elite Australian genotypes, Wang et al. (2015) identified 24 genomic regions controlling resistance to SFNB. We compared the positions of 225 previously reported markers associated with net blotch (NFNB and SFNB) with SNPs linked to MTAs we identified for field-scored net blotch, NFNB, and SFNB. We used blast analysis in Hordeum ensemble to obtain the physical position of markers used in previous studies. Several of our MTAs for field-scored net blotch have coincided with previously reported QTLs (Supplementary Table S4). Eleven of the 26 MTAs detected for field-scored net blotch were positioned within $10 \mathrm{Mbp}$ of previously reported QTLs or genes for net blotch. Qns-3H.1 was found to be $\sim 5.8 \mathrm{Mbp}$ away from Qpt.3H-1 reported by Vatter et al. (2017). Another MTA on $3 \mathrm{H}$, Qns-3H.4, was found to be $2.8 \mathrm{Mbp}$ away from the QTL reported by Burlakoti et al. (2017) and $\sim 2$ Mbp away from a QTL reported

Table 7. The barley genes found nearby the polymorphic sites for leaf scald

\begin{tabular}{lllll}
\hline MTA loci & \multicolumn{1}{c}{ Gene ID } & \multicolumn{1}{c}{ Description } & \multicolumn{1}{c}{ Functions } & \multicolumn{1}{c}{ Reference } \\
\hline Qsc-3H & HORVU3Hr1G111640 & Glutathione S-transferase GSTU6 & Disease resistance & Liao et al. (2014) \\
Qsc-6H.1 & HORVU6Hr1G001270 & Aldehyde dehydrogenase & Detoxification & Zhao et al. (2017) \\
& HORVU6Hr1G001290 & Subtilisin-like protease SBT1.7 & Plant-pathogen interaction & Figueiredo et al. (2014) \\
& HORVU6Hr1G001330 & Fruit bromelain & Disease resistance & Avrova et al. (1999) \\
Qsc-6H.1 & HORVU6Hr1G001350 & Wall-associated receptor kinase-like 6 & Stimuli perception & Yang et al. (2014) \\
Qsc-7H.1 & HORVU7Hr1G036380 & E3 ubiquitin-protein ligase ATL31-like & Regulating RLK & Goff and Ramonell (2007) \\
Qsc-7H.2 & HORVU7Hr1G042650 & Dehydration-responsive element-binding & Transcription factor & Singh et al. (2002) \\
& & protein & Defense signaling & Canonne et al. (2011) \\
Qsc-7H.4 & HORVU7Hr1G106580 & Patatin-like protein 3 & Defense signaling & Canonne et al. (2011) \\
& HORVU7Hr1G106600 & Patatin-like protein 3 & Defense signaling & Canonne et al. (2011) \\
& HORVU7Hr1G106610 & Patatin-like protein 3 & Transcription factor & Powell et al. (2017) \\
\hline
\end{tabular}


by Richards et al. (2017). Qsc-4H.1 was located about $0.8 \mathrm{Mbp}$ from the QTL reported for net blotch by Burlakoti et al. (2017) on chromosome $4 \mathrm{H}$. The MTA on $6 \mathrm{H}$ for field-scored net blotch (Qns-6H.4) is $0.4 \mathrm{Mbp}$ away from a QTL reported by Burlakoti et al. (2017). Qnb7H.1 is $4.1 \mathrm{Mbp}$ apart from a QTL reported by (Wonneberger et al. 2017).

Six of the seven MTAs we reported for NFNB were positioned in less than $10 \mathrm{Mbp}$ from previously reported QTLs and genes for NFNB (ST.1c). For example, Richards et al. (2016) located the Spt1 gene for NFNB on chromosome $6 \mathrm{H}$ approximately $0.24 \mathrm{cM}$ away from the markers rpt-M8 and SCRI_RS_165041. By blasting the anchor sequence associated with $S C R I \_R S \_165041$ in Hordeum Ensembl, we placed Sptl at the position $384,412,614$ bp on $6 \mathrm{H}$. This gene was found to be $\sim 0.46 \mathrm{Mbp}$ away from Qnfnb-6H.4 that we detected on chromosome $6 \mathrm{H}$. One of the QTLs reported by Amezrou et al. (2018) on $6 \mathrm{H}$ (QRptts-6H-54-55) was also located $5.9 \mathrm{Mbp}$ away from Qnfnb-6H.4. Similarly, we compared the location of the flanking markers of rpt.k and rpt.r loci for NFNB reported by Abu Qamar et al. (2008) with MTAs we found in this study for NFNB on chromosome $6 \mathrm{H}$. These markers include GBS0468 $(313,371,489$ bp), BE636841 (352,574,017 bp), ABC01797 (386,020,334 bp), and $A B C 02895$ (404,559,987 bp). The four MTAs we reported for NFNB on chromosome $6 \mathrm{H}$ were found between $353,473,922 \mathrm{bp}$ and $384,875,308 \mathrm{bp}$. Thus, MTAs identified in this study and those identified by Abu Qamar et al. (2008) mark the same region. The markers SCRI_RS_106581, reported by Richards et al. (2017), and SCRI_RS_148543, reported in T3/barley database, were located on $6 \mathrm{H}$ at the positions of $418,524,483 \mathrm{bp}$ and $422,777,022 \mathrm{bp}$, respectively. We detected a MTA for SFNB (Qsfnb-6H) on the same chromosome at position 422,811,909 bp located $\sim 4.3 \mathrm{Mbp}$ from the marker SCRI_RS_106581.

The three essential aspects of defense mechanisms of plants are (a) receiving signals of pathogen invasion, (b) signal perception and transduction, and (c) response to the pathogen, which involves extensive changes in cellular metabolism and increased gene activity (Somssich and Hahlbrock 1998). Therefore, several gene products are involved in the plant defense mechanisms. For example, accumulation of phytoalexins to detoxify phytotoxins produced by pathogens, modification of plant cell walls to block the diffusion of nutrients to microorganisms, retarded diffusion of phytotoxins from the pathogen to the plant cells, and accumulation of pathogenesisrelated proteins (PR-proteins) are all important responses to pathogens (Kuć 1997). The putative candidate genes found in this study are known to have roles in plant defense systems against biotic and abiotic stresses. Overall, we found at least 29 barley genes with predicted protein functions in plant defense for net blotch (both with natural and artificial inoculations) and leaf scald in barley.

The findings from this study identified sources of resistance and will help to design breeder-friendly markers, particularly for loci supported by previous research. In conclusion, our study provided information on genotypes that can be of value to breeding programs that improve leaf scald and net blotch resistance. The current study resulted in the identification of several barley genes with probable involvement in resistance mechanisms for leaf scald and net blotch. Finally, we suggest further functional genomics studies of the genes reported in this study.

\section{Acknowledgments}

The authors are thankful for the genotypes and seed received from EIAR and ICARDA. The authors thank Mr. Anberbir Haile and Mr. Shimelis Gezahegn for providing disease phenotyping opportunities in Ethiopia and thank Mr. Patrick Gross for providing help in field and greenhouse experimentation in Fargo.

\section{Literature Cited}

Abu Qamar, M., Liu, Z. H., Faris, J. D., Chao, S., Edwards, M. C., Lai, Z., Franckowiak, J. D., and Friesen, T. L. 2008. A region of barley chromosome $6 \mathrm{H}$ harbors multiple major genes associated with net type net blotch resistance. Theor. Appl. Genet. 117:1261-1270.

Adawy, S., Diab, A., Sayed, A. I., Ibrahim, S., El-Morsy, S. I., and Saker, M. M. 2013. Construction of genetic linkage map and QTL analysis of net blotch resistance in barley. Int. J. Adv. Biotechnol. Res. 4:348-363.
Amezrou, R., Verma, R. P. S., Chao, S., Brueggeman, R. S., Belqadi, L., Arbaoui, M., and Rehman, S., and Gyawali, S. 2018. Genome-wide association studies of net form of net blotch resistance at seedling and adult plant stages in spring barley collection. Mol. Breed. 38:58.

Avrova, A. O., Stewart, H. E., De Jong, W., Heilbronn, J., Lyon, G. D., and Birch, P. R. J. 1999. A cysteine protease gene is expressed early in resistant potato interactions with Phytophthora infestans. Mol. Plant-Microbe Interact. 12:1114-1119.

Bekele, H., Asnakech, T., Fekede, A., Melkamu, A., Getaneh, W., Yonas, W., Eshetu, A., and Birhanu, B. 2011a. Achievements of research on barley Helminthosporium diseases in Ethiopia. Pages 256-257 in: Barley Research and Development in Ethiopia. Proc. 2nd National Barley Res. Dev. Rev. Workshop. B. Mulatu and S. Grando, eds. ICARDA, Aleppo, Syria.

Bekele, H., Kiros, M., Fekede, A., Asnakech, T., Melkamu, A., Getaneh, W. Yonas, W., Eshetu, B., and Birhanu, B. 2011b. Achievements in Barley Scald research in Ethiopia. Pages 245-256 in: Barley Research and Development in Ethiopia. Proc. 2nd National Barley Res. Dev. Rev. Workshop. B. Mulatu and S. Grando, eds. ICARDA, Aleppo, Syria.

Bradbury, P. J., Zhang, Z., Kroon, D. E., Casstevens, T. M., Ramdoss, Y., and Buckler, E. S. 2007. TASSEL: Software for association mapping of complex traits in diverse samples. Bioinformatics 23:2633-2635.

Brunner, P. C., Schurch, S., and McDonald, B. A. 2007. The origin and colonization history of the barley scald pathogen Rhynchosporium secalis. J. Evol. Biol. 20:1311-1321

Burlakoti, R. R., Gyawali, S., Chao, S., Smith, K. P., Horsley, R. D., Cooper, B., Muehlbauer, G. J., and Neate, S. M. 2017. Genome-wide association study of spot form of net blotch resistance in the Upper Midwest barley breeding programs. Phytopathology 107:100-108.

Canonne, J., Froidure-Nicolas, S., and Rivas, S. 2011. Phospholipases in action during plant defense signaling. Plant Signal. Behav. 6:13-18.

Chen, L.-Q., Hou, B.-H., Lalonde, S., Takanaga, H., Hartung, M. L., Qu, X.-Q., Guo, W.-J., Kim, J.-G., Underwood, W., Chaudhuri, B., Chermak, D., Antony, G., White, F. F., Somerville, S. C., Mudgett, M. B., and Frommer, W. B. 2010. Sugar transporters for intercellular exchange and nutrition of pathogens. Nature 468:527-532.

Dao, T. T. H., Linthorst, H. J. M., and Verpoorte, R. 2011. Chalcone synthase and its functions in plant resistance. Phytochem. Rev. 10:397-412.

Ellis, M. B., and Waller, J. M. 1973. Pyrenophora Teres. [Descriptions of Fungi and Bacteria]. CAB International UK, ed. IMI Descriptions of Fungi and Bacteria, no. No. 39: Sheet 390.

Elshire, R. J., Glaubitz, J. C., Sun, Q., Poland, J. A., Kawamoto, K., Buckler, E. S., and Mitchell, S. E. 2011. A robust, simple genotyping-by-sequencing (GBS) approach for high diversity species. PLoS One 6:e19379.

Falconer, D. S., and Mackay, T. F. C. 1996. An Introduction to Quantitative Genetics, 4th ed. Prentice Hall, London.

Figueiredo, A., Monteiro, F., and Sebastiana, M. 2014. Subtilisin-like proteases in plant-pathogen recognition and immune priming: A perspective. Front. Plant Sci. 5:739

Garvin, D. F., Brown, A. H. D., Raman, H., and Read, B. J. 2000. Genetic mapping of the barley Rrs 14 scald resistance gene with RFLP, isozyme and seed storage protein markers. Plant Breed. 119:193-196.

Glaubitz, J. C., Casstevens, T. M., Lu, F., Harriman, J., Elshire, R. J., Sun, Q., and Buckler, E. S. 2014. TASSEL-GBS: A high capacity genotyping by sequencing analysis pipeline. PLoS One 9:e90346.

Goff, K. E., and Ramonell, K. M. 2007. The role and regulation of receptor-like kinases in plant defense. Gene Regul. Syst. Bio. 1:167-175.

Grewal, T. S., Rossnagel, B. G., Pozniak, C. J., and Scoles, G. J. 2008. Mapping quantitative trait loci associated with barley net blotch resistance. Theor. Appl Genet. 116:529-539.

Grewal, T. S., Rossnagel, B. G., and Scoles, G. J. 2012. Mapping quantitative trait loci associated with spot blotch and net blotch resistance in a doubled-haploid barley population. Mol. Breed. 30:267-279.

Gupta, S., Li, C., Loughman, R., Cakir, M., Westcott, S., and Lance, R. 2011 Identifying genetic complexity of $6 \mathrm{H}$ locus in barley conferring resistance to Pyrenophora teres $f$. teres. Plant Breed. 130:423-429.

Gupta, S., Li, C. D., Loughman, R., Cakir, M., Platz, G., Westcott, S., Bradley, J., Broughton, S., and Lance, R. 2010. Quantitative trait loci and epistatic interactions in barley conferring resistance to net type net blotch (Pyrenophora teres f. teres) isolates. Plant Breed. 129:362-368.

Hill, W. G., and Weir, B. S. 1988. Variances and covariances of squared linkage disequilibria in finite populations. Theor. Popul. Biol. 33:54-78.

Hofmann, K., Silvar, C., Casas, A. M., Herz, M., Büttner, B., Gracia, M. P., Contreras-Moreira, B., Wallwork, H., Igartua, E., and Schweizer, G. 2013. Fine mapping of the Rrs 1 resistance locus against scald in two large populations derived from Spanish barley landraces. Theor. Appl. Genet. 126: 3091-3102.

Islamovic, E., Bregitzer, P., and Friesen, T. L. 2017. Barley 4H QTL confers NFNB resistance to a global set of $P$. teres f. teres isolates. Mol. Breed. 37:29.

Jensen, J., Backes, G., Skinnes, H., and Giese, H. 2002. Quantitative trait loci for scald resistance in barley localized by a non-interval mapping procedure. Plant Breed. 121:124-128.

Kang, H. M., Sul, J. H., Service, S. K., Zaitlen, N. A., Kong, S., Freimer, N. B. Sabatti, C., and Eskin, E. 2010. Variance component model to account 
for sample structure in genome-wide association studies. Nat. Genet. 42: 348-354.

Knepper, C., Savory, E. A., and Day, B. 2011. The role of NDR1 in pathogen perception and plant defense signaling. Plant Signal. Behav. 6:1114-1116.

Kuć, J. 1997. Molecular aspects of plant responses to pathogens. Acta Physiol. Plant. 19:551-559.

Li, H., and Durbin, R. 2009. Fast and accurate short read alignment with Burrows-Wheeler Transform. Bioinformatics 25:1754-1760.

Li, H. B., and Zhou, M. X. 2011. Quantitative trait loci controlling barley powdery mildew and scald resistances in two different barley doubled haploid populations. Mol. Breed. 27:479-490.

Liao, W., Ji, L., Wang, J., Chen, Z., Ye, M., Ma, H., and An, X. 2014. Identification of glutathione S-transferase genes responding to pathogen infestation in populus tomentosa. Funct. Integr. Genomics 14:517-529.

Linde, C. C., Zala, M., and McDonald, B. A. 2009. Molecular evidence for recent founder populations and human-mediated migration in the barley scald pathogen Rhynchosporium secalis. Mol. Phylogenet. Evol. 51:454-464.

Liu, Z., Ellwood, S. R., Oliver, R. P., and Friesen, T. L. 2011. Pyrenophora teres: Profile of an increasingly damaging barley pathogen. Mol. Plant Pathol. 12:1-19.

Liu, Z. H., and Friesen, T. L. 2010. Identification of Pyrenophora teres f. maculata, causal agent of spot type net blotch of barley in North Dakota. Plant Dis. 94:480-480.

Manna, S. 2015. An overview of pentatricopeptide repeat proteins and their applications. Biochimie 113:93-99.

Manninen, O. M., Jalli, M., Kalendar, R., Schulman, A., Afanasenko, O., and Robinson, J. 2006. Mapping of major spot-type and net-type net-blotch resistance genes in the Ethiopian barley line CI 9819. Genome 49:1564-1571.

Mascher, M., Gundlach, H., Himmelbach, A., Beier, S., Twardziok, S. O., Wicker, T., Radchuk, V., Dockter, C., Hedley, P. E., Russell, J., Bayer, M., Ramsay, L., Liu, H., Haberer, G., Zhang, X. Q., Zhang, Q., Barrero, R. A., Li, L., Taudien, S., Groth, M., Felder, M., Hastie, A., Šimková, H., Staňková, H., Vrána, J., Chan, S., Muñoz-Amatriaín, M., Ounit, R., Wanamaker, S., Bolser, D., Colmsee, C., Schmutzer, T., Aliyeva-Schnorr, L., Grasso, S., Tanskanen, J., Chailyan, A., Sampath, D., Heavens, D., Clissold, L., Cao, S., Chapman, B., Dai, F., Han, Y., Li, H., Li, X., Lin, C., McCooke, J. K., Tan, C., Wang, P., Wang, S., Yin, S., Zhou, G., Poland, J. A., Bellgard, M. I., Borisjuk, L., Houben, A., Doležel, J., Ayling, S., Lonardi, S., Kersey, P., Langridge, P., Muehlbauer, G. J., Clark, M. D., Caccamo, M., Schulman, A. H., Mayer, K. F. X., Platzer, M., Close, T. J., Scholz, U., Hansson, M., Zhang, G., Braumann, I., Spannagl, M., Li, C., Waugh, R., and Stein, N. 2017. A chromosome conformation capture ordered sequence of the barley genome. Nature 544:427-433.

Money, D., Gardner, K., Migicovsky, Z., Schwaninger, H., Zhong, G., and Myles, S. 2015. LinkImpute: Fast and accurate genotype imputation for non-model organisms. G3: Genes|Genomes|Genetics 5 (11): 2383.

Neupane, A., Tamang, P., Brueggeman, R. S., and Friesen, T. L. 2015. Evaluation of a barley core collection for spot form net blotch reaction reveals distinct genotype-specific pathogen virulence and host susceptibility. Phytopathology 105:509-517.

Noordermeer, A. M., Gerrit, A., and Vliegenthart, J. F. G. 2001. Fatty acid hydroperoxide lyase: A plant cytochrome P450 enzyme involved in wound healing and pest resistance. ChemBioChem 2:494-504.

Paulitz, C. T., and Steffenson, B. J. 2011. Biotic stress in barley: Disease problems and solutions. Pages 307-354 in: Barley: Production, Improvement, and Uses. S. E. Ullrich, ed. Blackwell Publishing, Hoboken, NJ.

Powell, J. J., Carere, J., Sablok, G., Fitzgerald, T. L., Stiller, J., Colgrave, M. L., Gardiner, D. M., Manners, J. M., Vogel, J. P., Henry, R. J., and Kazan, K. 2017. Transcriptome analysis of Brachypodium during fungal pathogen infection reveals both shared and distinct defense responses with wheat. Sci. Rep. 7:17212.

R Core Team. 2013. R: A language and environment for statistical computing. R Foundation for Statistical Computing, Vienna, Austria. http://www.R-project.org/.
Richards, J., Chao, S., Friesen, T., and Brueggeman, R. 2016. Fine mapping of the barley chromosome $6 \mathrm{H}$ net form net blotch susceptibility locus. G3: Genes Genomes|Genetics 6 (7): 1809-1818

Richards, J. K., Friesen, T. L., and Brueggeman, R. S. 2017. Association mapping utilizing diverse barley lines reveals net form net blotch seedling resistance/ susceptibility Loci. Theor. Appl. Genet. 130:915-927.

Saari, E. E., and Prescott, J. M. 1975. A scale for appraising the foliar intensity of wheat disease. Plant Dis. Rep. 59:377-380.

Saintenac, C., Jiang, D., Wang, S., and Akhunov, E. 2013. Sequence-based mapping of the polyploid wheat genome. G3 (Bethesda) 3:1105-1114.

Shtaya, M. J. Y., Marcel, T. C., Sillero, J. C., Niks, R. E., and Rubiales, D. 2006 Identification of QTLs for powdery mildew and scald resistance in barley. Euphytica 151:421-429.

Singh, K. B., Foley, R. C., and Oñate-Sánchez, L. 2002. Transcription factors in plant defense and stress responses. Curr. Opin. Plant Biol. 5:430-436.

Somssich, I. E., and Hahlbrock, K. 1998. Pathogen defence in plants - a paradigm of biological complexity. Trends Plant Sci. 3:86-90.

Tekauz, A. 1985. A numerical scale to classify reactions of barley to Pyrenophora teres. Can. J. Plant Pathol. 7:181-183.

Tkaczuk, K. L., Shumilin, I. A., Chruszcz, M., Evdokimova, E., Savchenko, A., and Minor, W. 2013. Structural and functional insight into the universal stress protein family. Evol. Appl. 6:434-449.

Turner, S. D. 2014. Qqman: An R package for visualizing GWAS results using Q-Q and manhattan plots. bioRxiv . doi.org/10.1101/005165 http://cran.r-project org/web/packages/qqman/

Vatter, T., Maurer, A., Kopahnke, D., Perovic, D., Ordon, F., and Pillen, K. 2017 A nested association mapping population identifies multiple small effect QTL conferring resistance against net blotch (Pyrenophora Teres F. Teres) in wild barley. PLoS One 12:e0186803.

Wang, X., Mace, E. S., Platz, G. J., Hunt, C. H., Hickey, L. T., Franckowiak, J. D., and Jordan, D. R. 2015. Spot form of net blotch resistance in barley Is under complex genetic control. Theor. Appl. Genet. 128:489-499.

Wang, Y., and Bouwmeester, K. 2017. L-type lectin receptor kinases: new forces in plant immunity. PLoS Pathog 13:e1006433.

Wang, Y., Gupta, S., Wallwork, H., Zhang, X., Zhou, G., Broughton, S., and Loughman, R., Lance, R., Wu, D., Shu, X., and Li, C. 2014. Combination of seedling and adult plant resistance to leaf scald for stable resistance in barley. Mol. Breed. 34:2081-2089.

Williams, K., Bogacki, P., Scott, L., Karakousis, A., and Wallwork, H. 2001 Mapping of a gene for leaf scald resistance in barley line 'B87/14' and validation of microsatellite and RFLP markers for marker-assisted selection. Plant Breed. 120:301-304.

Williams, K. J., Lichon, A., Gianquitto, P., Kretschmer, J. M., Karakousis, A., Manning, S., Langridge, P., and Wallwork, H. 1999. Identification and mapping of a gene conferring resistance to the spot form of net blotch (Pyrenophora teres $f$ maculata) in barley. Theor. Appl. Genet. 99:323-327.

Wonneberger, R., Ficke, A., and Lillemo, M. 2017. Mapping of quantitative trait loci associated with resistance to net form net blotch (Pyrenophora teres f. teres) in a doubled haploid Norwegian barley population. PLoS One 12:e0175773.

Xiao, S., and Chye, M. 2011. New roles for Acyl-CoA-binding proteins (ACBPs) in plant development, stress responses and lipid metabolism. Prog. Lipid Res. 50:141-151.

Yang, K., Qi, L., and Zhang, Z. 2014. Isolation and characterization of a novel wall-associated kinase gene TaWAK5 in Wheat (Triticum Aestivum). Crop J. 2:255-266.

Zhang, Y., Lubberstedt, T., and Xu, M. 2013. The genetic and molecular basis of plant resistance to pathogens. J. Genet. Genomics 40:23-35.

Zhao, J., Missihoun, T. D., and Bartels, D. 2017. The role of Arabidopsis aldehyde dehydrogenase genes in response to high temperature and stress combinations. J. Exp. Bot. 68:4295-4308.

Zhu, C., Gore, M., Buckler, E. S., and Yu, J. 2008. Status and prospects of association mapping in plants. Plant Genome 1:5-20. 